\title{
Describing a novel chemotherapeutic drug formulated with diosmin for treatment of acute lymphoblastic leukemia and diabetes mellitus
}

\author{
Lili Wuํㄹ
}

\author{
1Department of Hematology, The Fourth Hospital of Hebei Medical University, \\ Shijiazhuang, Hebei, China \\ 2Department of Geriatrics, Nanjing Gaochun Hospital of Traditional Chinese Medicine, \\ Nanjing,Jiangsu,China \\ ${ }^{3}$ Department of Endocrinology, Aerospace Center Hospital,Beijing,China \\ ${ }^{4}$ Department of Blood Transfusion, Xi'an Children's Hospital, Xi'an, Shaanxi, China
}

Submitted: 16 October 2021; accepted: 17 November 2021

Online publication: 8 December 2021

Arch Med Sci

DOI: https://doi.org/10.5114/aoms/144053

Copyright $\odot 2022$ Termedia \& Banach

\begin{abstract}
Introduction: Diosmin is a natural citrus flavone with remarkable antioxidant and anti-inflammatory features. Acute leukemia is a common type of cancer of the blood.

Material and methods: $\alpha$-Amylase activity was determined by a method adapted from the work of Taha et al.

Results: In this study, we examined its effect on some important enzymes; the $I C_{50}$ values were 196.07 for aldose reductase, and 76.40 for $\alpha$-amylase. A molecular docking study was performed to assess the binding affinity and biological activities of diosmin in the presence of $\alpha$-amylase and aldose reductase. Discussion: The results of the docking study indicated that diosmin has a remarkable binding affinity to these enzymes with a docking score of $\mathbf{- 9 . 7 6 8}$ and -140469 for $\alpha$-amylase and aldose reductase, respectively. Therefore, this compound could be used as a potential inhibitor for these enzymes. In the cellular and molecular part of the recent study, the cells treated with diosmin were assessed by MTT assay for $48 \mathrm{~h}$ regarding the cytotoxicity and anti-human acute lymphoblastic leukemia properties on HL-60, Clone $15 \mathrm{HL}-60$, $\mathrm{HL}-60 / \mathrm{MX} 1$, and $\mathrm{HL}-60 / \mathrm{MX} 2$ cell lines. The $I \mathrm{C}_{50}$ values of diosmin were 466 , 323, 502, and $537 \mu \mathrm{g} / \mathrm{ml}$ against HL-60, Clone $15 \mathrm{HL}-60, \mathrm{HL}-60 / \mathrm{MX} 1$, and $\mathrm{HL}-60 / \mathrm{MX} 2$ cell lines, respectively.

Conclusions: The viability of acute lymphoblastic leukemia cell lines decreased dose-dependently in the presence of diosmin. It appears that the anti-human acute lymphoblastic leukemia effect of diosmin is due to its antioxidant effects.
\end{abstract}

Key words: diosmin, cytotoxicity, $\alpha$-amylase, aldose reductase, molecular modeling.

\section{Introduction}

Aldose reductase (AR) is a monomeric enzyme, weighing approximately $36 \mathrm{kDa}$, consisting of 315 amino acid sequences and located in the cell cytosol. Carper et al. [1] determined the primary structure of aldose reductase enzyme for the first time in rat lens. AR is an enzyme that, in the presence of NADPH cofactor, converts aldehydes originating from free oxygen radicals (ROS) into inactive alcohols as well as reducing

\author{
Corresponding author: \\ Qian Hou \\ Department of \\ Blood Transfusion \\ Xi'an Children's \\ Hospital \\ Xi'an, Shaanxi, China \\ E-mail: houqian2222@sina. \\ com
}


glucose to sorbitol [2]. In cells with high AR activity, the depletion of NADPH causes an increase in GSH level, thus increasing oxidative stress [3]. As a result of many studies, it is thought that the aldose reductase enzyme is responsible for the reduction of $D$-glucose to $D$-sorbitol in the polyol pathway [4] and this reaction is associated with complications of diabetes in hyperglycemia. The three-dimensional structure of AR was revealed by $X$-ray crystallography analysis. Inhibitors interact with the active site of the AR because the active site of the AR enzyme has a flexible structure. AR is a cytosolic enzyme and is distributed in the lens of the eye, retina, kidney, adrenal gland, and reproductive organs [5]. $\alpha$-Amylase has a very important role in the treatment of diabetes. Inhibition of this enzyme delays glucose secretion and absorption in the small intestine. In this event that takes place in the intestine, the level of hyperglycemia is reduced by delaying carbohydrate digestion by inhibitors of enzymes [6, 7].

Molecular docking has recently emerged as a versatile method for the investigation of biological activities of chemical compounds. This method as a theoretical approach could provide a more detailed view of interactions and mechanisms between ligand-enzyme complexes [8]. This method can provide valuable information about the various characteristics of the interactions that occur between chemical compounds and biological materials. The obtained data from the outcomes of the docking study can give the knowledge that biologists need to understand the mechanisms in which an inhibitor could stop the enzyme activity [9].

Acute leukemia is a common type of cancer that affects the blood. In severe situations of acute leukemia, immunotherapy, chemotherapy, radiation therapy, and surgery are administered for the treatment of acute leukemia [10-13]. Chemotherapeutic drugs have many side effects, so finding a new drug with the efficacy of the chemotherapeutic drugs and without any side effect is very valuable. In this regard, many studies have proven excellent anticancer properties of biotechnological materials such as antioxidant molecules [13].

In the recent study, the properties of prepared diosmin against acute lymphoblastic leukemia (HL60, Clone $15 \mathrm{HL}-60, \mathrm{HL}-60 / \mathrm{MX} 1$, and HL-60/MX2) cell lines and diverse enzymes were evaluated.

\section{Material and methods}

\section{Anti-acute lymphoblastic leukemia properties of diosmin}

The process of the controlled culture of prokaryotic or eukaryotic cells in a filtered or unfiltered flask or cell culture plate by a suitable culture medium is called DMEM. This term is mostly used for culturing multicellular cells. Special culture media are used to culture cells. The cells are usually cultured at $37^{\circ} \mathrm{C}$ in equipment such as $\mathrm{CO}_{2}$ incubators. Cell culture should be performed under aseptic (disinfected) conditions because the growth of these cells is much slower than the growth of bacteria and yeasts and there is a possibility of contamination of the culture medium. Antibiotics such as penicillin, streptomycin, or gentamicin are sometimes used to stop the growth of bacteria. In order for cells to proliferate well in culture medium, their density in culture medium must be low. For this purpose, the cells should be passed to fresh culture medium from time to time. One of the goals of cell culture is to study cells in terms of how they grow, their nutritional needs, and the reasons they stop growing, each of which can have a profound effect on the morphology of the cells we see under a microscope. Therefore, to study the cell growth cycle, develop methods to control the growth of cancer cells and modulate the expression of genes, it is necessary to cultivate these cells in the external environment [14].

With the help of cell culture, cells can be prepared that are in different stages of differentiation and can be differentiated into other cells with the help of hormones and growth factors. With the help of cell culture, homogeneous cells can be prepared and intracellular activities such as DNA replication, DNA transcription synthesis, RNA and protein synthesis and other details related to metabolism can be studied. It is also possible to examine the subsequent events and intracellular currents, such as the displacement of these complexes, the type of intracellular messages, and how the messages are transmitted, after connecting different molecules to the corresponding membrane receptor. The cultured cells can be stored frozen at very low temperatures. Such conditions will maintain the growth rate or genetic composition of these cells and they can be thawed and used again at the appropriate time. This prevents the aging of cells, while it is currently not possible to prevent the aging of animals. When working with laboratory animals, systemic changes due to the effect of the animal's natural homeostasis or the stress of the experiments on the results should be considered, while the use of cell culture eliminates this problem. In addition, standardizing laboratory tests is easier and more practical than tests on living organisms. In laboratory environments, it is much easier to control the physical and chemical factors in the living environment of cells, including acidity, heat, osmotic pressure, and the pressure of gases such as oxygen and carbon dioxide. Cells that are taken directly from the individual are known as primer cells and have a limited lifespan. Most cells have a limited lifespan, except for those taken from a tumor. An immortal cell line can proliferate indefinitely by 
creating a random or targeted mutation (such as artificial gene expression) and be established as a representative of specific cell types [14].

In this research, we used the following cell lines to evaluating anti-acute lymphoblastic leukemia and cytotoxicity effects of diosmin using an MTT method.

a) Normal cell line: HUVEC.

b) Human acute lymphoblastic leukemia cell lines: $\mathrm{HL}-60$, Clone $15 \mathrm{HL}-60, \mathrm{HL}-60 / \mathrm{MX} 1$, and HL-60/ MX2.

In the recent study, the cells were cultured in medium (RPMI $1640=$ Roswell Park Memorial Institute 1640 ) with $10 \%$ FBS combined with penicillin and streptomycin antibiotics in an incubator containing $5 \% \mathrm{CO}_{2}$ in a flask (T25). After three passages for purification, the cells were used to perform the next steps. Cell count and the number of viable cells were performed with a hemocytometer slide using trypan blue. Evaluation of the cytotoxic effect of the diosmin was performed by the modified 3-(4,5-dimethylthiazol-2-yl)-2,5-diphenyl-2H-tetrazolium bromide (MTT) colorimetric test. In this method, MTT, which is yellow, is converted to insoluble formazan purple dye by the dehydrogenase enzymes in the mitochondria of active cells. The adsorption of this compound can be measured after dissolving at 570-540 nm. After 2 days and covering the flask bottom with cells, the cell layer adhering to the flask bottom was isolated enzymatically using trypsin-EDTA (5\%) (tetraacetic acid ethylenediamine); after transfer to sterile test tubes, it was centrifuged at $2000 \mathrm{rpm}$ for $10 \mathrm{~min}$. The cells were then resuspended in a fresh culture medium with the help of a Pasteur pipette and cell suspension $\left(10^{6} \mathrm{ml} / \mu \mathrm{g}\right)$ was prepared from them. $40 \mu \mathrm{l}$ of this cell suspension (equivalent to $10^{4} \times 4$ cells) was poured into flat-bottomed wells of a 96-well plate (for cell culture). Then the final volume of each well with $10 \%$ FBS medium reached $200 \mu \mathrm{l}$. The first row containing cell suspension was considered as a negative control (control). After incubation for 18-24 $\mathrm{h}$ to remove cells from the stress caused by trypsinization, the supernatant was removed slowly and carefully. A new medium was added to all rows with different concentrations of diosmin (only new medium was added to the negative and positive control rows), so that the diluted diosmin with concentrations of $1-1000 \mu \mathrm{g} / \mathrm{ml}$ was added to the third to sixth rows, respectively; the plate was incubated in $\mathrm{CO}_{2}$ for 48, 24 and $72 \mathrm{~h}$. After the incubation time, the plate was taken out of the incubator and $20 \mu \mathrm{l}$ of MTT (Sigma) was added to all wells, and incubated for $3 \mathrm{~h}$. The supernatant was then gently removed and $100 \mu \mathrm{l}$ of DMSO was added to the wells and pipetted to dissolve the formazan crystals. The amount of light absorption
(OD) according to the intensity of the blue color of formazan at $540 \mathrm{~nm}$ was read by ELISA reader. To convert $\mathrm{OD}$ to the percentage of living cells, the following formula was used and the percentage of live cells at each concentration was calculated after 48, 24 and 72 h [14]: Cell viability $(\%)=($ Sample A/Control A) $\times 100$.

The concentration of the tested compounds that reduced the percentage of live cells by half was considered as $I C_{50}$ (the half maximal inhibitory concentration) [14].

\section{Qualitative measurement}

At least three independent replications were performed for each data set and the result was presented as mean \pm SD. Statistical analysis of data was done with SPSS software version 22 and one-way ANOVA and Duncan tests. Significance was considered at the level of $p \leq 0.05$.

\section{Enzyme methods}

$\alpha$-Amylase activity was determined by a method adapted from the work of Taha et al. [15] Accordingly, $\alpha$-amylase solution, phosphate buffer and starch from the reaction components were incubated in an Eppendorf tube at $35^{\circ} \mathrm{C}$ for $10 \mathrm{~min}$. $100 \mu \mathrm{l}$ of dinitrosalicylic acid (DNS) was added to the reaction and the reaction mixture was boiled for $5 \mathrm{~min}$ to stop the reaction. The reaction mixtures cooled to room temperature were diluted with $1000 \mu \mathrm{l}$ of distilled water and absorbance measurements were performed at $540 \mathrm{~nm}$ [16]. One unit of enzyme activity was calculated as the amount of $1 \mu \mathrm{mol}$ maltose released in $1 \mathrm{~min}$ under the reaction conditions. For AR, these solutions were used: $1 \mathrm{M}$ Na-phosphate buffer, $\mathrm{pH}=$ 5.5, 0.11 mM NADPH solution, and 4.7 mM DL-glyceraldehyde solution. The activity measurement of the AR enzyme was performed by modifying the procedure used by Cerelli et al. [17]. The reaction medium was prepared by adding $50 \mu \mathrm{l}$ of isolated enzyme to $250 \mu \mathrm{l}$ of Na-phosphate buffer, $100 \mu \mathrm{l}$ of $\mathrm{NADPH}$ and $500 \mu \mathrm{l}$ of distilled water. The reaction was initiated by adding $100 \mu \mathrm{l}$ of DL-glyceraldehyde to the cuvette prepared above. The decrease in NADPH concentration at $340 \mathrm{~nm}$ and room temperature was followed by a spectrophotometer for $3 \mathrm{~min}$. Then, intervals with linear absorbance values were determined and slope calculations were made. For the $\mathrm{IC}_{50}$ study, we obtained different activities using different inhibitor concentrations and calculated the percent activities and obtained them in graph form. We repeated them 3 times [18].

\section{Molecular docking study}

A molecular docking study as a versatile theoretical approach was used to evaluate the bio- 
logical activities of diosmin as an inhibitor for $\alpha$-amylase and aldose reductase numerically. For this purpose, the structures of human pancreatic $\alpha$-amylase (PDB ID: 1HNY) [19] and human aldose reductase (PDB ID: 1US0) [20] were downloaded from the PDB database (http://www.rcsb.org/ $p d b)$. The unprocessed structure is not ready to be used for a docking study. Therefore, a preparation process has to be done. Some of the main steps are the addition of hydrogen atoms to the structure, water molecule removal, creation of a $\mathrm{H}$-bond network, and minimization of the system. The minimization step was carried out us ing the OPLS3e force field. All of the preparation processes were performed using the preparation module of the Schrödinger Suite [21]. The structure of diosmin was obtained from the PubChem database in SDF format, and the correct molecular geometries were produced using the LigPrep module of Schrödinger [22]. The suitable protonation states were also produced using the Epik module. The binding sites of the enzyme structure were predicted, and their related scores were determined using SiteMap of Schrödinger [23]. A grid of $20 \times 20 \times 20 \AA^{3}$ was created around the first predicted active site. Finally, Glide of Schrödinger suites was utilized to perform molecular docking investigations.

\section{Results and Discussion}

Cytotoxicity and anti-acute lymphoblastic leukemia activities of diosmin

Cancer is recognized as one of the leading causes of death in today's society and several drugs have been introduced to treat this disease, but, most common cancers are not yet controllable and this disease imposes huge costs on the patient and society. The main factor in the development and progression of cancer has not yet been precisely identified; however, the available data suggest that metabolic disorders in the tissue and immune disorders may be involved in the development and exacerbation of this disease [24-26]. In addition, metabolic disorders in the production and excretion of oxygen free radicals are important factors affecting cancer cells. Free radicals are destructive compounds that are produced as a by-product by the body's chemical reactions and are destroyed by the body's defense system and enzyme system and antioxidants. However, in cases where the body's metabolic disorders and the production of free radicals are high and they are not destroyed by the neutralizing system, due to their instability, these compounds have a strong tendency to react with a variety of molecules in the body [26-29]. It is estimated that each cell in the human body is exposed to free radicals 10,000 times a day and DNA strands 5,000 times a day. Damage to cell components includes proteins (genetic disorder), fats (lipid oxidation), and cell membranes (permeability disorder); if the damage is not repaired, it leads to disruption of the chemical reaction and normal proteinization of the cell and the formation of harmful compounds and sometimes cancer cells in the body $[25,27]$. It is reported that thousands of cancer cells are produced daily in the human body that are killed by the body's defense system. In some cases, due to dysfunction of the above systems, cancer cells proliferate and conditions for cancer development in different tissues occur. According to the above, antioxidants play a vital role in preventing disorders caused by the effects of free radicals and thus the prevention and treatment of cancer. Antioxidants are a wide range of molecular compounds with complex properties that combine with and neutralize free radicals. The results show that more than 60,000 types of molecular antioxidants have been identified so far. Antioxidants can be effective in three known ways to prevent and treat cancer: 1. Destruction of free radicals 2 . Strengthening the immune system to destroy cancer cells. 3. Prevention of adhesion of cancer cells to other cells and prevention of their proliferation [24-29].

In this experiment, the cells treated with different concentrations of diosmin were assessed by MTT assay for $48 \mathrm{~h}$ regarding the cytotoxic properties towards normal (HUVEC) and acute lymphoblastic leukemia cell lines, i.e. HL-60, Clone $15 \mathrm{HL}-60$, HL-60/MX1, and HL-60/MX2.

The viability of acute lymphoblastic leukemia cell lines decreased dose-dependently in the presence of diosmin. The $I C_{50}$ values of diosmin were 466, 323, 502, and $537 \mu \mathrm{g} / \mathrm{ml}$ against $\mathrm{HL}-60$, Clone 15 HL-60, HL-60/MX1, and HL-60/MX2 cell lines, respectively (Figures $1-3$ ). The absorbance rate was evaluated at $570 \mathrm{~nm}$, which represented viability on the normal cell line (HUVEC) even up to $1000 \mu \mathrm{g} / \mathrm{ml}$ for diosmin (Figure 3).

It seems that the anti-acute lymphoblastic leukemia effect of the investigated molecule is due to its antioxidant effects. Because tumor progression is so closely linked to inflammation and oxidative stress, a compound with anti-inflammatory or antioxidant properties can be an anticarcinogenic agent [30]. Many molecules have pharmacological and biochemical properties, including antioxidant and anti-inflammatory properties, which appear to be involved in anticarcinogenic and antimutagenic activities [31]. Today, molecules synthesized by biological methods play a vital role in treating many diseases, including cancer [32]. Molecules synthesized by biological methods are no longer the only ones in traditional medicine; in addition, they have been able to adopt an industrial line of natural products for treating various cancers. Var- 
A

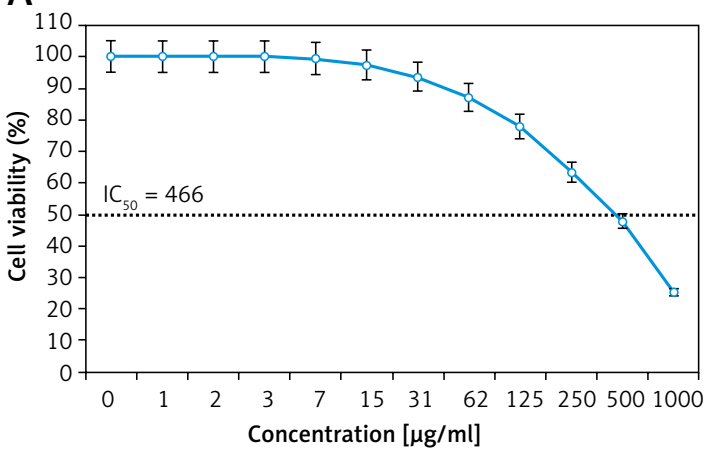

B

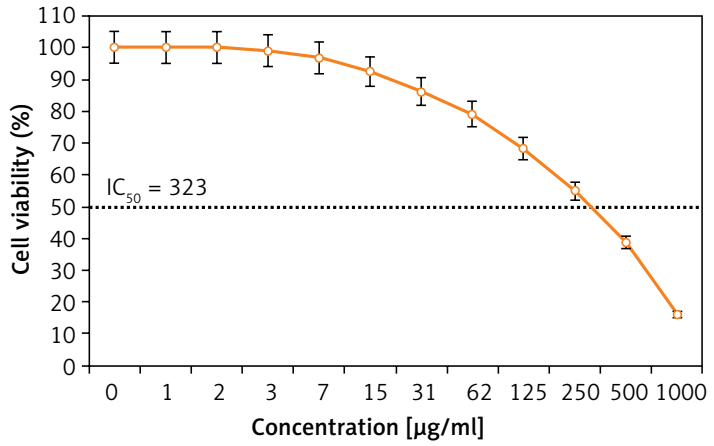

Figure 1. Anti-acute lymphoblastic leukemia properties (cell viability (\%)) of diosmin (concentrations of 0-1000 $\mu \mathrm{g} / \mathrm{ml}$ ) against acute lymphoblastic leukemia (HL-60 (A), and Clone 15 HL-60 (B)) cell lines

A

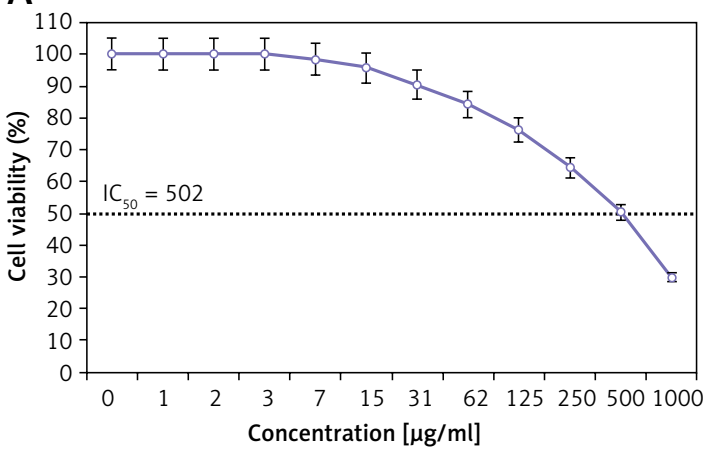

B

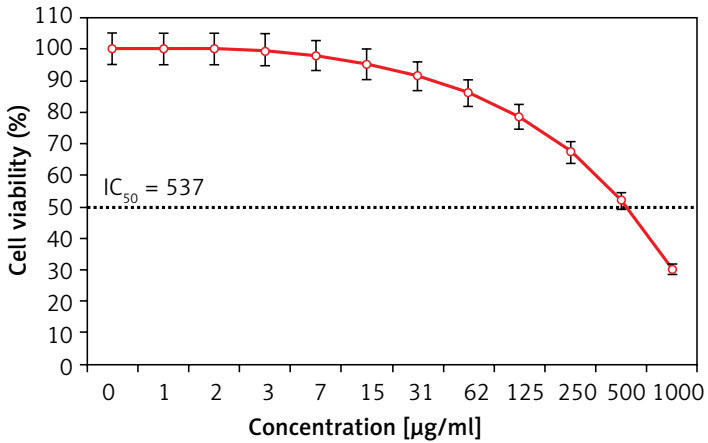

Figure 2. Anti-acute lymphoblastic leukemia properties (cell viability (\%)) of diosmin (concentrations of 0-1000 $\mu \mathrm{g} / \mathrm{ml}$ ) against acute lymphoblastic leukemia (HL-60/MX1 (A) and HL-60/MX2 (B)) cell lines

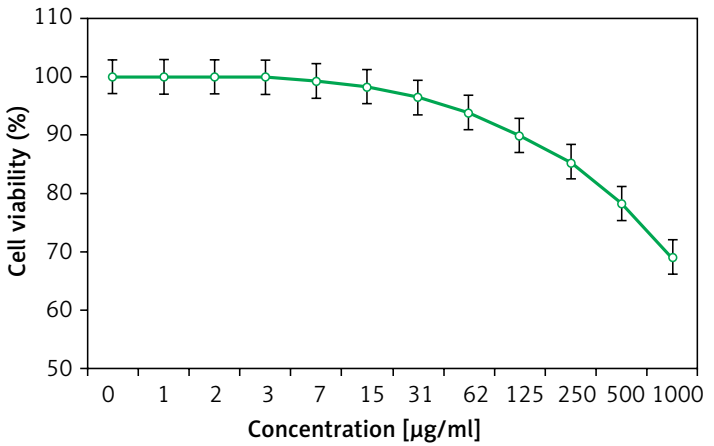

Figure 3. Cytotoxic properties (cell viability (\%)) of diosmin (concentrations of $0-1000 \mu \mathrm{g} / \mathrm{ml}$ ) against human normal (HUVEC) cell line

ious cell lines from cancers of the prostate, ovary, lung, liver, and pancreas have been treated with synthesized herbal molecules [33].

\section{Enzyme results}

Naturel compounds containing benzene rings are generally known as "phenolic compounds". Hydroxybenzene, known as 'phenol', in other words, benzene carrying one hydroxyl group, is the simplest form of phenolic compounds [34]. All other phenolic compounds are derived from hydroxybenzene. In this study, the effect of dios- min as a natural compound on AR and $\alpha$-amylase was investigated. Indeed, we examined its effect on some important enzymes; the $\mathrm{IC}_{50}$ values were 196.07 for aldose reductase, and 76.40 for $\alpha$-amylase. Glucosidase inhibitors are highly promising in the treatment of various diseases such as diabetes, viral infections and cancer metastasis, as well as being a very effective tool for understanding the mechanism of action of glucosidases [35]. Therefore, $\alpha$-amylase has been the target enzyme for the design of drug molecules suitable for the treatment of diabetes, obesity, and hyperglycemia [36]. Limonoids purified from Azadirachta indica for pancreatic $\alpha$-amylase inhibition have also been reported to be used as antidiabetic drugs because of their potential therapeutic effects. In addition, it has been stated that tetracyclic diterpenoid (also known as isosteviol) triazole derivatives obtained by acid hydrolysis of steviol glycoside extract, which is abundant in Stevia rebaudiana, are used as antitumor agents in cancer treatment [37]. Aldose reductase inhibitors are used in nephropathy and retinopathy. Ocular retinopathy occurs as a result of accumulation of sorbitol. Aldose reductase enzyme inhibitors (sorbinil, tolrestat, ponalrestat, epalrestat, flavonoid) may also be effective in the treatment of diabetic glomerulosclerosis (hardening of the kidney capillaries) [38]. 


\section{Molecular modeling results}

A molecular docking study was conducted for the investigation of biological and chemical activities of diosmin against two enzymes, human pancreatic $\alpha$-amylase, and human aldose reductase. The docking pose of the compound in the presence of $\alpha$-amylase is presented in Figure 4 , and the interactions created by diosmin between this ligand and the enzyme are shown in Figure 5. The results show that the number of hydrogen bonds between diosmin and $\alpha$-amylase is seven bonds which have caused a strong binding affinity with a docking score of -9.768 (Table I). Asp197 is a very active residue in the enzyme structure, as it has created three hydrogen bonds with diosmin. These hydrogen bonds are crucial since Asp197 is one of the essential members of the catalytic domain of $\alpha$-amylase [39]. Glu233 is another residue that has created a hydrogen bond with diosmin, and like Asp197, this residue is one of the catalytic residues of $\alpha$-amylase [39]. These essential hydrogen bonds show that diosmin is able to inhibit enzyme activity considerably. The other residues with hydrogen bond interaction are Thr 1 and 63Arg195. As can be seen in Figure 5, twelve other residues have created hydrophobic contacts with the ligand. Asp300 is one of these residues, and since this residue is a catalytic residue [39], this hydrophobic contact is an important interaction. Figure 6 presents the docking pose of diosmin against aldose reductase, and the characteristics of their interactions are shown in Figure 7. As it is apparent, there are three hydrogen bonds between diosmin and the residues of aldose reductase. The residues that have created hydrogen bonds are Lys21, Gln49, and Asp160. There are a large number of hydrophobic interactions between various residues of aldose reductase and diosmin. Tyr48 and His110 are among twelve residues with hydrophobic contacts. These two residues are the catalytic residues of the enzyme $[40,41]$, which means that these two hydrophobic contacts are crucial interactions for the inhibitory activity of diosmin. The parameters obtained from docking calculations are shown in Table I. One of the most essential parameters among the calculated parameters is the docking score [42] This value for $\alpha$-amylase and aldose reductase is -9.768 and -14.469 , respectively, which show a remarkable binding affinity of diosmin for these two enzymes. Another parameter is the Glide Ligand Efficiency, which is a parameter showing the energy between molecules and their related binding partner. The Van der Waals energy is shown with Glide Evdw, and Glide Ecoul indicates the Coulomb energy. The Glide energy is the numerically calculated energy of the interaction, and the Glide Emodel is the interaction pose value [43] These results indicate that diosmin has the potential to be used as an inhibitor for both $\alpha$-amylase and aldose reductase. The lower amount of $\mathrm{IC}_{50}$ for $\alpha$-amylase could probably be attributed to the number of hydrogen bonds that have been created by diosmin. This number is seven for $\alpha$-amylase and four for aldose reductase.

In conclusion, we determined the antidiabetic properties of the compound we used in the study. Molecular docking could provide valuable information about the interactions, mechanisms, and biological activities of a chemical compound in the presence of biological material such as enzymes. The outcomes of docking calculations revealed that diosmin has a remarkable binding affinity to $\alpha$-amylase and aldose reductase, which means this compound is a potential inhibitor for these enzymes. These inhibitory activities could be related to a large number of hydrogen bonds and hydrophobic contacts, which could be created by diosmin. The viability of acute lymphoblastic leukemia cell lines decreased dose-dependently in the presence of diosmin. The $\mathrm{IC}_{50}$ values of dios-

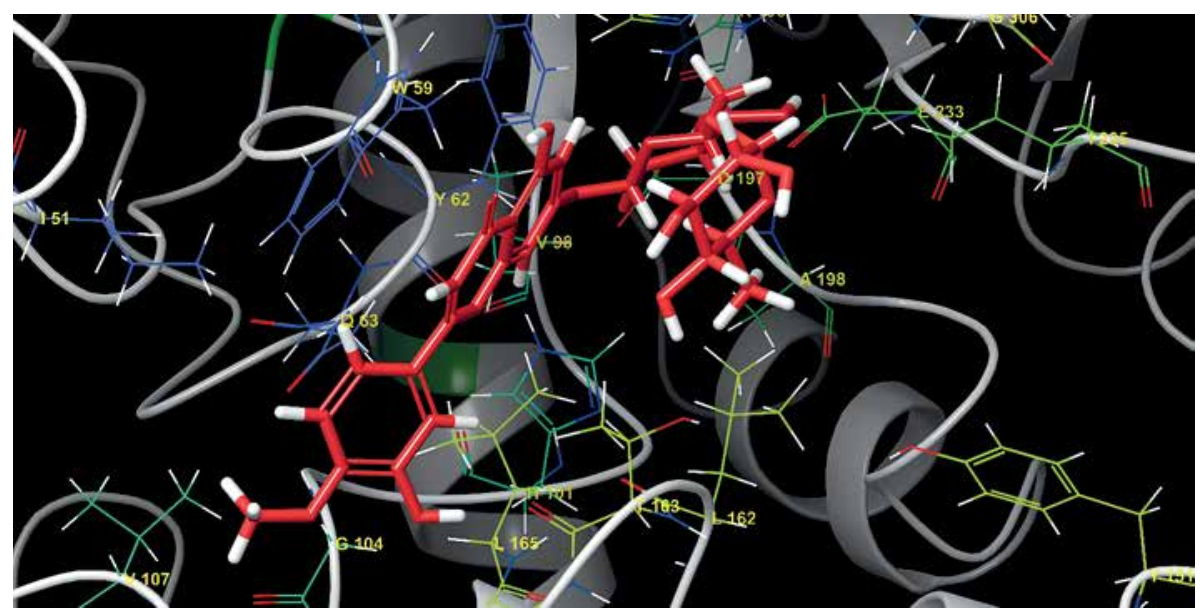

Figure 4. The docking pose of diosmin among alpha amylase residues 


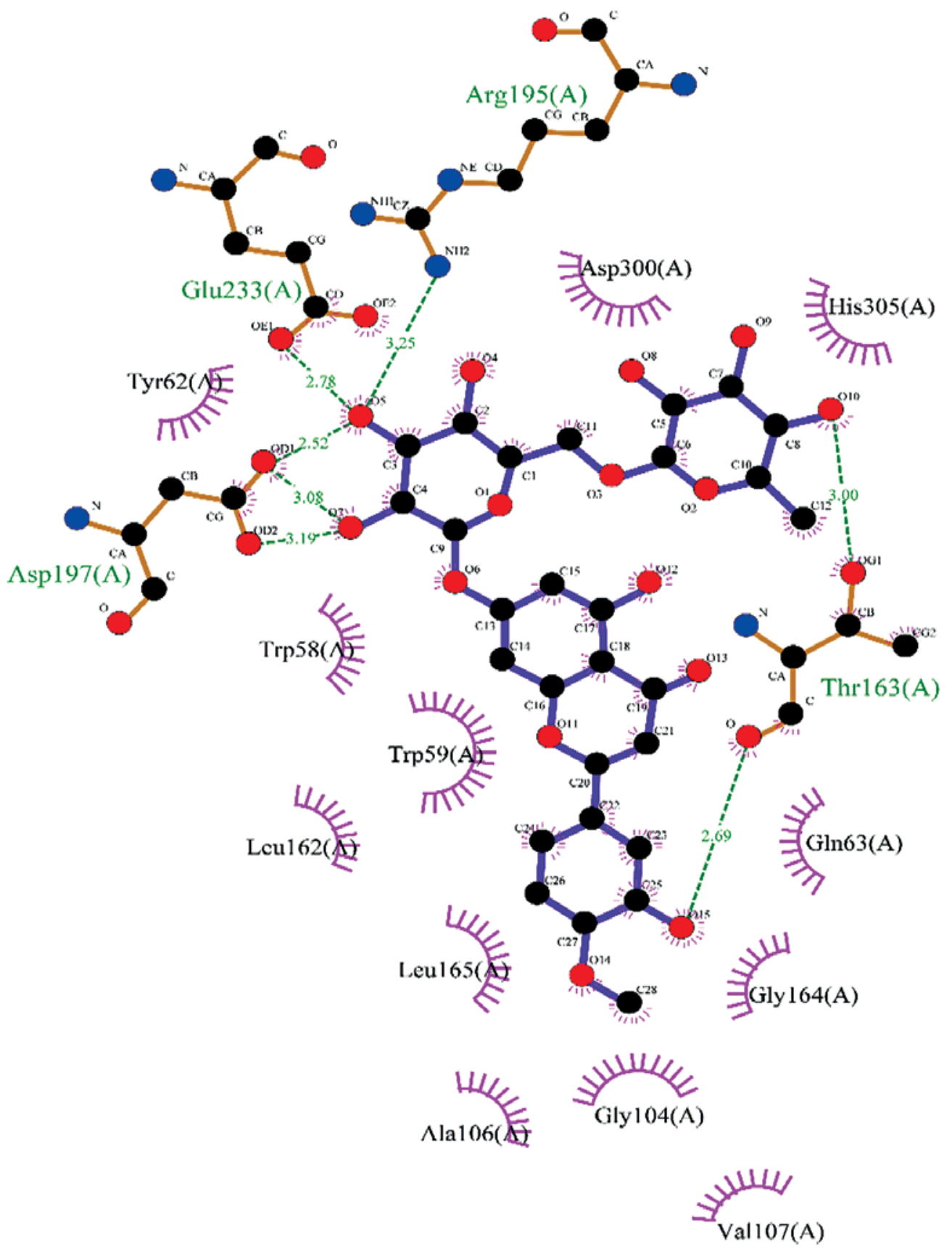

Figure 5. The interactions created by diosmin and $\alpha$-amylase. Green dashed lines show the hydrogen bonds, and semicircles are the hydrophobic contacts

Table I. Parameters obtained from the molecular docking calculations

\begin{tabular}{|lcc|}
\hline Parameter & $\alpha$-Amylase & Aldose reductase \\
\hline $\mathrm{IC}_{50}[\mathrm{mM}]$ & 76.40 & 196.07 \\
\hline Docking score $[\mathrm{kcal} / \mathrm{mol}]$ & -9.768 & -14.469 \\
\hline Glide ligand efficiency $[\mathrm{kcal} / \mathrm{mol}]$ & -0.227 & -0.336 \\
\hline Glide Ecoul $[\mathrm{kcal} / \mathrm{mol}]$ & -24.252 & -15.013 \\
\hline Glide Evdw $[\mathrm{kcal} / \mathrm{mol}]$ & -39.650 & -44.165 \\
\hline Glide Emodel $[\mathrm{kcal} / \mathrm{mol}]$ & -91.484 & -82.645 \\
\hline Glide energy $[\mathrm{kcal} / \mathrm{mol}]$ & -63.903 & -59.178 \\
\hline
\end{tabular}




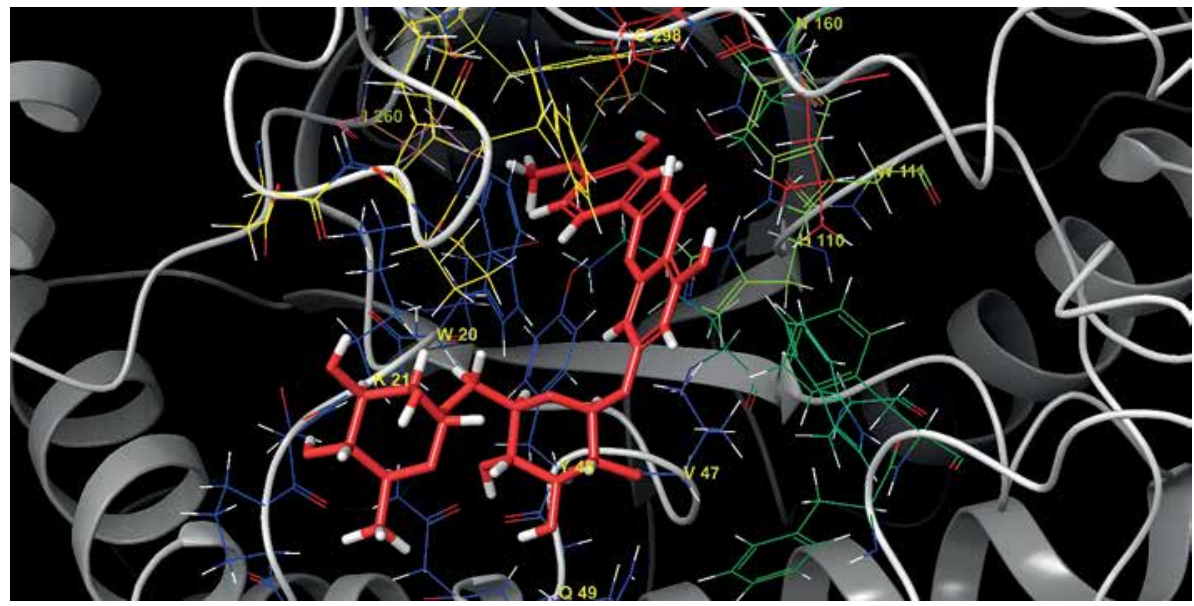

Figure 6. The docking pose of diosmin among the residues of aldose reductase

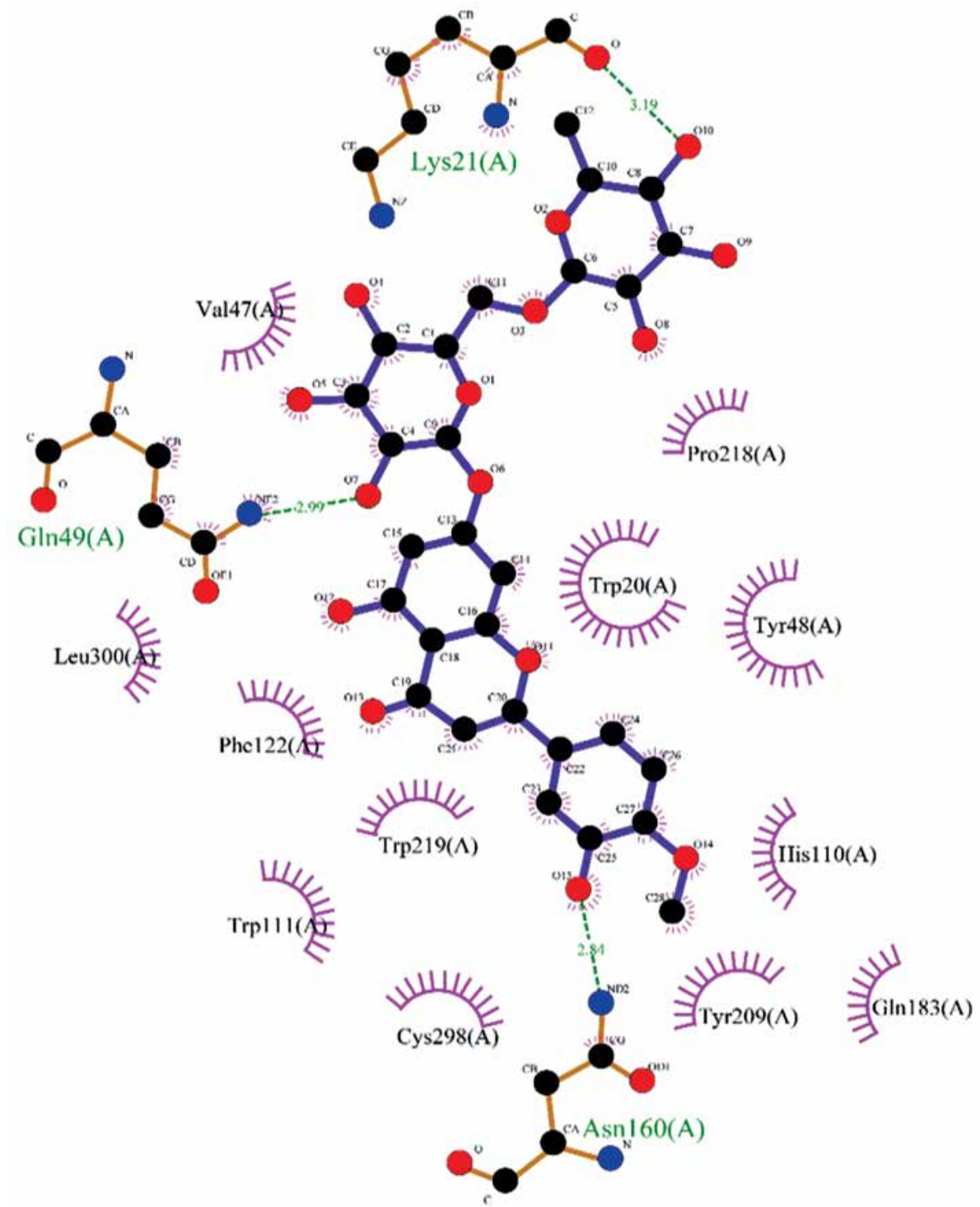

Figure 7. The interactions of diosmin and aldose reductase. Green dashed lines show the hydrogen bonds, and semicircles represent the hydrophobic contacts 
$\min$ were $466,323,502$, and $537 \mu \mathrm{g} / \mathrm{ml}$ against HL-60, Clone $15 \mathrm{HL}-60, \mathrm{HL}-60 / \mathrm{MX} 1$, and HL-60/ MX2 cell lines, respectively.

\section{Acknowledgments}

Lili Wu is $1^{\text {st }}$ author and Lei Xing is co- $1^{\text {st }}$ author.

\section{Conflict of interest}

The authors declare no conflict of interest.

\section{References}

1. Tang WH, Stitham J, Gleim S, et al. Glucose and collagen regulate human platelet activity through aldose reductase induction of thromboxane. J Clin Invest 2011; 121: 4462-76.

2. Sun W, Oates PJ, Coutcher JB, Gerhardinger C, Lorenzi M. A selective aldose reductase inhibitor of a new structural class prevents or reverses early retinal abnormalities in experimental diabetic retinopathy. Diabetes 2006; 55: 2757-62.

3. Ramana KV, Friedrich B, Bhatnagar A, Srivastava SK. Aldose reductase mediates cytotoxic signals of hyperglycemia and TNF-alpha in human lens epithelial cells. FASEB J 2003; 17: 315-7.

4. Kador F, Kinoshita H, Stribling D, Brittain R, Mirrless J, Sennitt M. Rat lens aldose reductase and polyol production: a reply. J Biochem 1987; 247: 295-6.

5. Nambu H, Kubo E, Takamura Y, Tsuzuki S, Tamura M, Akagi Y. Attenuation of aldose reductase gene suppresses high-glucose-induced apoptosis and oxidative stress in rat lens epithelial cells. Diabetes Res Clin Pract 2008; 82: 18-24.

6. Nambu H, Kubo E, Takamura Y, Tsuzuki S, Tamura M, Akagi Y. Attenuation of aldose reductase gene suppresses high-glucose-induced apoptosis and oxidative stress in rat lens epithelial cells. Diabetes Res Clin Pract 2008; 82: 18-24.

7. Okechukwu P, Sharma M, Tan WH, et al. In-vitro anti-diabetic activity and in-silico studies of binding energies of palmatine with alpha-amylase, alpha-glucosidase and DPP-IV enzymes. Pharmacia 2020; 67: 363-71.

8. Anuar NF, Wahab RA, Huyop F, et al. Molecular docking and molecular dynamics simulations of a mutant Acinetobacter haemolyticus alkaline-stable lipase against tributyrin. J Biomol Structure Dynamics 2021; 39: 2079-91.

9. Jhong CH, Riyaphan J, Lin SH, Chia YC, Weng CF. Screening alpha-glucosidase and alpha-amylase inhibitors from natural compounds by molecular docking in silico. BioFactors 2015; 41: 242-51.

10. GBD 2015 Disease and Injury Incidence and Prevalence, Collaborators. "Global, regional, and national incidence, prevalence, and years lived with disability for 310 diseases and injuries, 1990-2015: a systematic analysis for the Global Burden of Disease Study 2015". Lancet 2016; 388: 1545-602.

11. Wolach O, Stone RM. How I treat mixed-phenotype acute leukemia. Blood 2015; 125: 2477-85.

12. Abdel-Fattah WI, Ali GW. On the anti-cancer activities of silver nanoparticles. J Appl Biotechnol Bioeng 2018; 5: 43-6.

13. Lu Y, Wan X, Li L, Sun P, Liu G. Synthesis of a reusable composite of graphene and silver nanoparticles for catalytic reduction of 4-nitrophenol and performance as anti-colorectal carcinoma. J Materials Res Technol 2021; 12: 1832-43.

14. Aman S, Gupta UK, Singh D, Khan T. Herbal treatment for the ovarian cancer. SGVU J Pharm Res Educ 2018; 3: 325-9.

15. Taha M, Javid MT, Imran S, et al. Synthesis and study of the $\alpha$-amylase inhibitory potential of thiadiazole quinoline derivatives. Bioorg Chem 2017; 74: 179-86.

16. Yousuf S, Khan KM, Salar U, et al. 2'-Aryl and 4'-arylidene substituted pyrazolones: as potential $\alpha$-amylase inhibitors. Eur J Med Chem 2018; 159: 47-58.

17. Cerelli MJ, Curtis DL, Dunn JP, Nelson PH, Peak TM, Waterbury LD. Antiinflammatory and aldose reductase inhibitory activity of some tricyclic arylacetic acids. J Med Chem 1986; 29: 2347-51.

18. DeRuiter J, Swearingen BE, Wandrekar V, Mayfield CA. Synthesis and in vitro aldose reductase inhibitory activity of compounds containing an $\mathrm{N}$-acylglycine moiety. J Med Chem 1989; 32: 1033-8.

19. Brayer GD, Luo Y, Withers SG. The structure of human pancreatic $\alpha$-amylase at $1.8 \AA$ resolution and comparisons with related enzymes. Protein Sci 1995; 4: 1730-42.

20. Howard El, Sanishvili R, Cachau RE, et al. Ultrahigh resolution drug design I: details of interactions in human aldose reductase-inhibitor complex at $0.66 \AA$. Proteins Struct Funct Genet 2004; 55: 792-804.

21. Schrödinger Release 2020-4: Protein Preparation Wizard; Epik, Schrödinger, LLC, New York, NY 2016; Impact, Schrödinger, LLC, New York, NY 2016; Prime, Schrödinger, LLC, New York, NY 2020.

22. Schrödinger Release 2020-4: LigPrep, Schrödinger, LLC, New York, NY 2020.

23. Poustforoosh A, Hashemipour H, Tüzün B, Pardakhty A, Mehrabani M, Nematollahi MH. Evaluation of potential anti-RNA-dependent RNA polymerase (RdRP) drugs against the newly emerged model of COVID-19 RdRP using computational methods. Biophys Chem 2021; 272: 106564.

24. Gao J, Wang Z, Liu H, Wang L, Huang G. Liposome encapsulated of temozolomide for the treatment of glioma tumor: preparation, characterization and evaluation. Drug Discov Ther 2015; 9: 205-12.

25. Mohammed MI, Makky AM, Teaima MH, Abdellatif MM, Hamzawy MA, Khalil MA. Transdermal delivery of vancomycin hydrochloride using combination of nano-ethosomes and iontophoresis: in vitro and in vivo study. Drug Deliv 2016; 23: 1558-64.

26. Zhang C, Zhou X, Zhang H, et al. Recent progress of novel nanotechnology challenging the multidrug resistance of cancer. Front Pharmacol 2022; 13: 776895.

27. Yang F, Jin C, Jiang Y, et al. Liposome based delivery systems in pancreatic cancer treatment: from bench to bedside. Cancer Treat Rev 2011; 37: 633-42.

28. Ding H, Zhang S, Liu X. Applications of nanocarriers with tumor molecular targeted in chemotherapy. Chemistry 2012; 75: 621-7.

29. Allen TM. Ligand-targeted therapeutics in anticancer therapy. Nat Rev Cancer 2002; 2: 750-63.

30. Byrne JD, Betancourt T, Brannon-Peppas L. Active targeting schemes for nanoparticle systems in cancer therapeutics. Adv Drug Del Rev 2008; 60: 1615-26.

31. Torchilin VP. Targeted pharmaceutical nanocarriers for cancer therapy and imaging. AAPS J 2007; 9: E128-47.

32. Deshpande PP. Current trends in the use of liposomes for tumor targeting. Nanomedicine 2013; 8: 1509-28.

33. Zhang Y, Huang Y, Li S. Polymeric micelles: nanocarriers for cancer-targeted drug delivery. AAPS Pharm Sci Tech 2014; 15: 862-71. 
34. Teodor ED, Moroeanu V, Radu GL. Lignans from medicinal plants and their anticancer effect. Mini Rev Med Chem 2020; 20: 1083-90.

35. Granger DA, Kivlighan KT, Blair C, et al. Integrating the measurement of salivary alpha-amylase into studies of child health, development, and social relationships. J Soc Personal Relationships 2006; 23: 267-90.

36. Van Lenten SA, Doane LD. Examining multiple sleep behaviors and diurnal salivary cortisol and alpha-amylase: Within- and between-person associations. Psychoneuroendocrinology 2016; 68: 100-10.

37. Bright MA, Frick JE, Out D, Granger DA. Individual differences in the cortisol and salivary alpha-amylase awakening responses in early childhood: relations to age, sex, and sleep. Develop Psychobiol 2014; 56: 1300-15.

38. DeRuiter J, Brubaker AN, Whitmer WL, Stein JL Jr. Synthesis and aldose reductase inhibitory activity of substituted 2-oxoquinoline-1-acetic acid derivatives. J Med Chem 1986; 29: 2024-8.

39. Poustforoosh A, Hashemipour H, Tüzün B, Pardakhty A, Mehrabani M, Nematollahi MH. Evaluation of potential anti-RNA-dependent RNA polymerase (RdRP) drugs against the newly emerged model of COVID-19 RdRP using computational methods. Biophys Chem 2021; 272: 106564.

40. Barski OA, Gabbay KH, Grimshaw CE, Bohren KM. Mechanism of human aldehyde reductase: characterization of the active site pocket. Biochemistry 1995; 34: 1126475

41. Dréanic MP, Edge CM, Tuttle T. New insights into the catalytic mechanism of aldose reductase: a QM/MM study. ACS Omega 2017; 2: 5737-47.

42. Subhani S, Jayaraman A, Jamil K. Homology modelling and molecular docking of MDR1 with chemotherapeutic agents in non-small cell lung cancer. Biomed Pharmacother 2015; 71: 37-45.

43. Türe A, Kahraman DC, Cetin-Atalay R, Helvacıoğlu S, Charehsaz M, Küçükgüzel İ. Synthesis, anticancer activity, toxicity evaluation and molecular docking studies of novel phenylaminopyrimidine-(thio)urea hybrids as potential kinase inhibitors. Comput Biol Chem 2019; 78: 227-41. 